Challis professorship of biology was instituted in 1889 , appointed him to the chair, without advertisementat the time a most unusual proceeding - and this he held continuously until his retirement in 1917. All through these years his scientific activity continued unabated.

In 1893 Haswell published, in the Macleay Memorial Volume, his great monograph on the Temnocephaleæ, a group which occupied his attention right up to the end of his working days, for the last paper he wrote is entitled "Critical Notes on the Temnocephaloidea," and was published in the Proc. Linn. Soc. N.S.W. so recently as December 29,1924 . In the volume above mentioned he also described the remarkable new type, Actinodactylella, from the gill-cavities of the Gippsland burrowing crayfish, Engceus fossor. In numerous papers, published mainly in the Q.J.M.S. and the Proc. Linn. Soc. N.S.W., he contributed largely to our knowledge of the Turbellaria, both fresh-water and marine, and the Cestoda, and by his discovery of the histriobdellid, Stratiodrilus, and his detailed accounts of its anatomy and development, he greatly extended our knowledge of the "Archi-annelida," whilst to him we are indebted for the only available account of the early development of the Port Jackson shark (Heterodontus).

Outside the ranks of professional zoologists, Haswell is perhaps best known to the scientific world as the joint-author, with his staunch friend the late Prof. T. Jeffrey Parker; of the monumental "Text-book of Zoology," which, issued in 1898 , is now in its second edition and is accepted as a standard text-book in zoological laboratories all over the English-speaking world.

Amidst all his academic work Haswell found time to take an active interest in the various Australian scientific organisations. He was for long on the Council of the Linnean Society of N.S.W., and acted as its president in $1892-93$; he was president of Section D of the Australasian Association for the Advancement of Science in $\mathrm{I} 89 \mathrm{I}$, and he was for many years a trustee of the Australian Museum. In IgI 6 he edited the Reports of the Australasian Antarctic Expedition.

Haswell was a man of wide knowledge and culture. Shy and somewhat reserved in disposition, he was a loyal, warm-hearted, and ever helpful friend and a kindly and charming host. He was a keen trout-fisher, enjoyed a game of golf, and was an ardent gardener. In I894 he married Josephine Gorden Rich, a pupil of Jeffrey Parker and joint-author with him of a paper on the myology of Palinurus, and she always took a lively interest in her husband's work. She and an only daughter survive him.

Haswell was elected a fellow of the Royal Society in 1897 , and was a member of numerous societies both at home and abroad.

The writer will ever bear his old chief in grateful memory for the forbearance and many kindnesses he showed him during an association of some fourteen years.

J. P. H.

\section{Prof. John Cleland, F.R.S.}

Prof. John Cleland, who died on March 5, in his ninetieth year, held the chair of anatomy in Queen's College, Galway, from 1863 until 1877 . In the latter year he succeeded Dr. Allen Thomson as occupant of the chair of anatomy in the University of Glasgow, which he held until r 909 , retiring at the age of seventyfour to spend the happy evening of his days at Crewkerne, Somerset.

Cleland was a man of imposing appearance who impressed on the generations of students who passed through his class-rooms his love of knowledge, his wide culture, and independence of outlook. He was beloved by his students. All his life long he was fighting a rear-guard action. He was born and bred in preDarwinian days and grew up in the school represented by John Goodsir and Richard Owen. He believed in evolution-particularly the brand represented in the "Vestiges of Creation." He could not abide the dogmatic assurance with which Huxley proceeded to sweep the "underlying element of spirit" from all biological processes. For him Darwin's law of "Natural Selection "was true and potent, but in his opinion this law was powerless in the production of purposive adaptations. He was a student of "morphological design " and believed that a "unity of cause" worked through "the ordered sequence to be seen in all biological events." The "morphological beauty of the skull " was almost one of his religious tenets. Those who know the researches and writings of John Goodsir will realise how strong was the influence which the master exerted on John Cleland seventy years ago. With him goes the last representative of the transcendental and philosophical anatomists of the nineteenth century.

Cleland was born in Perth in 1835 , the son of a medical man. He was turned from the Church to medicine by his mother, and began his studies in the University of Edinburgh in 1852 . Goodsir, then a man of thirty-eight, was at the height of his fame and immersed in researches of the most diverse kinds, but was particularly enamoured of Owen's speculations regarding the "original design" which was supposed to underlie the head and body segments of vertebrate animals. When Cleland became junior demonstrator to John Goodsir in 1857 - Sir William Turner was then senior demonstrator-he applied himself chiefly to the morphological problems of the vertebræ and of the skull. He published many dissections made on rarer animals, but the work he will be best remembered by is that done on the human skull. Unfortunately, in 1857 , Goodsir's great gifts were already being sapped by the disorder which carried him off ten years later; it is vain to speculate now as to the course events would have followed if Goodsir had retained his full powers of mind; his disease certainly fanned his tendency towards transcendentalism, and it was this side of his mind which had the strongest influence on his junior demonstrator.

In 186I Cleland left Edinburgh to demonstrate anatomy under Prof. Allen Thomson of the University of Glasgow, one who was a master of scientific method. In I863 he was appointed to his first chair, in Queen's College, Galway. His best known research was done while he was there, and was published in the Philosophical Transactions (1870, vol. 160, p. I17), on " An Enquiry into the Variations of the Human Skull, particularly in the Antero-posterior Direction." This inquiry has not received the attention it deserves, for in NO. 2890 , VOL. I 15$]$ 
it Cleland directed attention to the remarkable changes in shape which the human skull passes through at various stages of growth of the child and at later phases of life. Even in adult years head form is not fixed ; significant changes may occur in the later decades of life. Between 1855 and 1906 he published more than fifty separate papers and covered a variety of subjects. He was a poet and published a book of verse, "Scala Naturae" (I887); a volume of essays, "Evolution, Expression, and Sensation" (I88I); he was one of the editors of the seventh edition of Quain's "Anatomy" (I867); with his former pupil, now Principal J. Yule Mackay of University College, Dundee, he wrote a textbook on "Anatomy (Human Anatomy, General and Descriptive)," I896, and a "Directory for the Dissection of the Human Body" (1877).

A. $\mathrm{K}$.

\section{DR. A. DE WAtteville.}

Dr. DE WAtTeville, whose death, at the age of seventy-eight, occurred in Switzerland on February 24 last, was a prominent member of the medical profession in London between twenty and thirty years ago. A Swiss by birth, scion of one of the oldest families of Switzerland, he was an Englishman by education, and qualified for the medical profession. He specialised in neurology, and more particularly in electro-therapeutics, which he did much to establish on a scientific basis. His work on "Medical Electricity," which ran through two editions - the second in I884established his reputation as the chief authority on the subject in Great Britain. He specially insisted on measurements of current strength as the essential condition of a rational application of electricity, and led to the milliampere being adopted as the electro-therapeutic unit by the International Congress of Electricians.

It was, however, as editor of Brain that Dr. de Watteville found his chief interest and occupation. In I 883 he became associated as co-editor with the original founders and editors of this important journal-the late Sir J. C. Bucknill, Dr. Hughlings Jackson, Sir J.
Crichton-Browne, and Sir David Ferrier-and in 1886 was appointed sole editor, when Brain became the official journal of the newly founded Neurological Society. This post he held until rgoo. On his resignation the council of the Neurological Society by unanimous resolution paid him the following well-merited tribute :

The Council accepts with great regret Dr. de Watteville's resignation of the Editorship of Brain, and desires to take this opportunity of recording the deep debt of gratitude that the Society owes him for the way in which he has conducted the Journal for the past twenty years. The Council feels that parting with Dr. de Watteville is an event of great moment to the Society, for he has not only brought Brain to a high standard of perfection and secured for it a great European reputation, but even the existence of the Journal at the present time is due to his energetic action at a critical juncture in I880. Moreover, the Council is mindful that the Society itself took origin on Dr. de Watteville's initiative at a meeting held at his house on November I 4,1885 .

Soon after resigning the editorship of Brain, Dr. de Watteville left London and went to reside in Switzerland, and spent the remainder of his life in quiet study and contemplation among the beautiful surroundings of his native land. Dr. de Watteville was a man of wide culture and great force of character, charitable and self-sacrificing almost to a fault, and the outspoken foe of quackery and pretence of every description.

D. F.

WE regret to announce the following deaths:

Dr. W. F. Hillebrand, chief chemist of the U.S. Bureau of Standards, who was distinguished for his work on rock and mineral analysis, on February 7 , aged seventy-one.

Prof. A. von Wassermann, emeritus professor of experimental therapy and immurology in the University of Berlin and director of the Kaiser Wilhelm Institute for Experimental Therapy in Berlin-Dahlem, on March I6, aged fifty-nine.

\section{Current Topics and Events.}

Elsewhere in this issue is an article by Prof. Raymond Dart dealing with certain evidence which, on his view, reveals a long history of cultural contact between South Africa and the outside world from an early date. It is scarcely necessary to emphasise the importance of Prof. Dart's views in relation to the "diffusionist" theories which have been put forward by Prof. Elliot Smith and his colleagues. Perhaps the most striking piece of evidence with which Prof. Dart deals is the parallel drawn between the head-dress and clothing of certain figures in the Bushmen paintings of the Kei River Valley and of figures in the art of Babylonia and Western Asia. Bushmen paintings are thought by some, for good reason, to be relatively modern; the evidence of the incrustation of which Prof. Dart speaks is of little value without further information as to its character and rate of deposit. If the identification of the Babylonian cap were accepted, it would suggest the eighth century B.c. as a probable date, but NO. 2890 , vOL. I I 5$]$ without a strong corroborative evidence the identification is precarious, especially as this type of cap is of extreme rarity in Babylonian art. Prof. Dart is on surer ground when he points to the problem presented by the extensive traces of early mining activity in Rhodesia. It may be that the researches of the Committee of the British Association which is investigating the composition of early bronzes may point to South Africa as one of the possible sources of supply and thus afford some clue to the date of some of these workings. It is, however, beyond question that the discovery by Dr. Randall-MacIver in the ruined structures of Rhodesia of Nankin china which could not be dated at the earliest much before the fourteenth century, is a great stumbling-block in the way of those who seek to prove an early date for the Zimbabwe culture.

WITH the past two or three weeks reports have reached Great Britain of a new experiment carried 